\title{
Ph-Like Acute Lymphoblastic Leukemia
}

National Cancer Institute

\section{Source}

National Cancer Institute. Ph-Like Acute Lymphoblastic Leukemia. NCI Thesaurus. Code C121974.

A leukemia subtype characterized by a gene-expression profile similar to that of BCRABL1-positive acute lymphoblastic leukemia, alterations of lymphoid transcription factor genes, and a poor outcome. 